Nephron 1971;8:413

\title{
Editorial of the President of the International Society of
}

\section{Nephrology}

As of January 1, 1972, the International Society of Nephrology's Journal will be published by Springer-Verlag of New York, Heidelberg and Berlin. Because of this change, the Journal of the International Society of Nephrology will be called Kidney International after this date.

I would like to take this opportunity to thank S. Karger for his help in creating the International Society of Nephrology's Journal. The present Editors of the Society's Journal, Dr. G. Richet, Dr. J. Dormont and Dr. G. E. Schreiner, are retiring. The Society is greatly indebted to these three individuals for the work they have put in during the past 8 years in nurturing the Society's Journal from its beginning to the excellent position it now holds. Dr. Roscoe R. Robinson of Duke University Medical Center, Durham, N.C., will assume the Editorship of Kidney International on January 1, 1972.

H. E. de Wardener

President of the International Society of Nephrology 